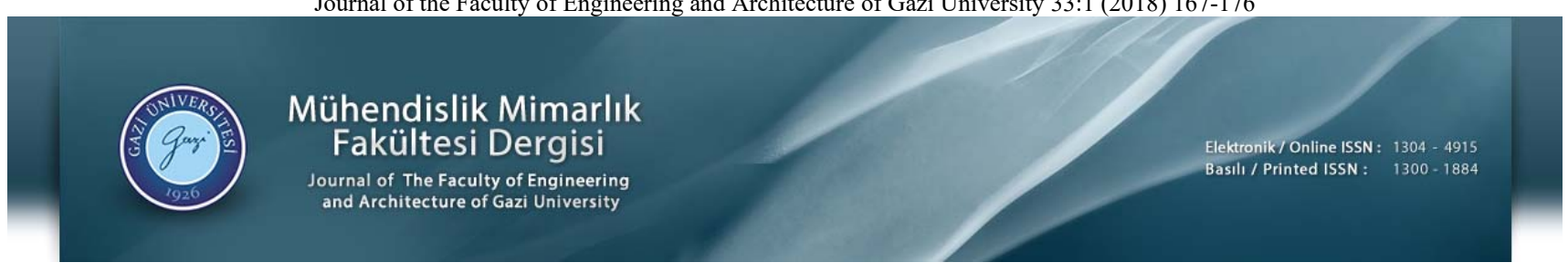

\title{
Betondaki boşlukların darbe-eko ve ultrasonik-eko yöntemleri ile görüntülenmesi
}

Sena Tayfur*(i), Ninel Alver(D)

Ege Üniversitesi, İnşaat Mühendisliği Bölümü, Bornova, İzmir, 35100, Türkiye

Ö N E Ç I K A N L A R

- Betondaki boşlukların görüntülenmesi

- Elastik dalga yayılımını temel alan tahribatsız muayene yöntemleri

- $\quad$ Malzeme karakterizasyonu

Makale Bilgileri

Geliş: 29.09.2016

Kabul: 03.05.2017

DOI:

$10.17341 /$ gazimmfd.406789

Anahtar Kelimeler:

elastik dalga,

darbe-eko,

ultrasonik-eko,

boşluk tespiti

\section{ÖZET}

Darbe-eko (Impact-echo, IE) ve ultrasonik-eko (Ultrasonic-echo, UE) betondaki boşlukların belirlenmesinde yaygın olarak kullanılan elastik dalga yöntemlerindendir ve bu alanda başarılı uygulamaları mevcuttur. Ancak çoğu zaman bu yöntemlerden elde edilen sonuçların yorumlanmasında çeşitli zorluklarla karşılaşılması sebebiyle araştırmacılar görüntüleme algoritmalarını geliştirmeye çalışmaktadırlar. $\mathrm{Bu}$ çalışmada beton bloklarda yer alan boşlukların değerlendirilmesi için SIBIE (Darbe-Eko'da Spektral Genliklerin Toplanarak Görsellenmesi) ve SAFT (Yapay Açıklıklı Odaklanma Tekniği) algoritmaları kullanılmıştır. Bu amaçla boşluklu metal ard germe kanalı içeren beton bloklar üretilmiş ve boşlukların yerlerini belirlemek için IE ve UE deneyleri gerçekleştirilmiştir. Ayrıca literatürdeki diğer çalışmalardan farklı olarak farklı kalınlıklardaki ard germe kanallarının ultrasonik sinyalin faz değișimine etkisi belirlenmiştir. Çalışma sonunda başarılı bir boşluk görüntülemesinin yanı sıra, hava ve çeliğin akustik empedans karakteristikleri açısından ayırt edici bir malzeme karakterizasyonu gerçekleştirilmiştir.

\section{Imaging of voids in concrete by impact-echo and ultrasonic-echo methods}

\section{H I G H L I G H T S}

- Imaging of voids in concrete

- Nondestructive testing methods based on elastic wave propagation

- Material characterization

Article Info

Received: 29.09 .2016

Accepted: 03.05.2017

DOI:

10.17341/gazimmfd.406789

Keywords:

Elastic wave, impact-echo, ultrasonic-echo, void detection

\section{ABSTRACT}

Impact-echo (IE) and ultrasonic-echo (UE) are widely used elastic wave methods to determine voids in concrete and have successful applications in the field. However, because in most cases it is difficult to interpret the results, researchers have been studying on to develop imaging algorithms. In this study, SIBIE (Stack Imaging of Spectral Amplitudes Based on IE) and SAFT (Synthetic Aperture Focusing Technique) algorithms were used in order to evaluate voids within concrete blocks. For this purpose, concrete blocks containing post-tensioning ducts that include voids were produced and IE and UE tests were carried out to locate the voids. Moreover, apart from the other studies in literature, effect of thickness of the metal ducts on phase change of the ultrasonic signal was determined. As a result of the study, along with successful void visualization, material characterization by means of acoustic impedance characteristics of air and steel was made.

\footnotetext{
*Sorumlu Yazar/Corresponding Author: sena.tayfur@ege.edu.tr/ Tel: +90 2323886026
} 


\section{GIRISŞ (INTRODUCTION)}

Yap1lar servis ömürleri boyunca imalat hataları, deprem gibi ani yükler ve çevresel etkilerden kaynaklanan çeşitli hasarlara uğramaktadır. $\mathrm{Bu}$ hasarlar genellikle boşluk oluşumu, çatlama, beton yüzeyinin tanelenmesi ve delaminasyonlardır. $\mathrm{Bu}$ tür hasarların tespiti ve değerlendirmesi için kullanılan test yöntemlerinden bazıları test süresince yapiya zarar vermekte ve entegre bilgi vermezken, bazıları tahribatsıdır ve bütünsel bilgi edinimi sağlamaktadır. Darbe-eko (IE) ve Ultrasonik-eko (UE) da s1klıkla kullanılan tahribatsız muayene yöntemlerindendir [1]. Her iki yöntem de bir kaynak tarafindan oluşturulan elastik dalgaların malzeme içerisinde yayılması ve bu dalgaların hız ve yansımalarının ölçülmesi esasına dayanmaktadır. IE'de mekanik bir etki ile malzeme yüzeyinde geçici bir gerilme pulsu oluşturulur [2]. Bu puls ile malzemede yayılan dalgalar zaman-tanım aralığında bir sinyal olarak kaydedildikten sonra, Hızlı Fourier Dönüşümü (FFT) ile frekans-tanım aralığına dönüştürülmekte ve dalga yansımasının frekansının hesaplanması ile malzeme tabaka kalınlığı veya bünyesindeki hasarın lokasyonu tahmin edilebilmektedir. Literatürde IE yönteminin geliştirilmesine ilişkin çok sayıda çalışma mevcuttur. Hsiao vd. [2] tarafından yapılan çalışmada hasarlı ve hasarsız beton blokların darbe davranışlarının IE yöntemi ile belirlenmesi amaçlanmış ve hasarın varlığı ile titreşim modlarında bozulmalar meydana geldiği ortaya konmuştur. Ayrıca gözlenen baskın frekans değerinin daha düşük değerlere ötelenmesi ve maksimum genlik değerinin hasarı tespit etmedeki önemi ortaya konmuştur. Zhu ve Popovics [3] çalışmalarında betonun hasar tespitinde temassız IE yöntemini uygulamışlar ve geniş frekans aralıklı temassız sensörlerin döşemelerin darbe davranışı hakkında daha iyi sonuçlar verdiğini belirtmişlerdir.

Epasto vd.'in [4] çalışmasında IE'nin betondaki yangın hasarının belirlenmesinde dalgacık zaman-frekans tekniği kullanılmıştır. FFT analizine dayalı geleneksel yaklaşımın baskın frekansı belirlemede önem arz ettiği, ancak CWT (Sürekli Dalgacık Dönüşümü) analizinin bu frekansın hasarın derinliğiyle ilişkilendirilmesinde FFT'ye göre daha çok sayıda parametre ve hızlı tespit olanağı sağladığını ortaya çıkarmışlardır. Bhaskar vd. [5] tarafından IE ile beton tabaka kalınlığı ve ardgerme kanallarındaki harç dolu/boşluklu bölgeler belirlenebilmiştir. Çalışmada önerilen önemli husus ise, tarama yapılacak noktaların numune çeperi ve geometrik değişiklik gibi süreksizlikler içeren yüzeylerden uzakta seçilmesidir. Olson vd. [6] çalışmalarında ard germeli beton köprülerdeki hasarları IE ile belirleyebilmiş, Chaudhary [7] ise benzer çalışmasında elemanların büyüklük ve şekillerinin önemini ve geometrik korelasyon katsayısının gerçek boyutlu yapısal elemanlara göre düzeltilmesi gerektiğini vurgulanmıştır. Ardından Azari vd. [8] beton döşemelerin performans değerlendirmesinde IE ve ultrasonik yüzey dalgalarından faydalandikları çalışmalarında her iki yöntemin de kalınlık ve diğer parametrelere bağlı olarak hassasiyetlerinin farklılık gösterdiğini belirtmişlerdir. Gomez vd. [9] iki tabakalı bir sistemden elde edilen IE frekans spektrumlarının ancak dalga hızının iki tabakada da birbirine çok yakın olması durumunda tek tabakalı sistemlerdeki kadar kolay ayırt edilebildiğini görmüşler ve iki tabakalı sistemler için tabakalara ait dispersiyon eğrilerinin kullanımı ile piklerin rahatlıkla karakterize edildiğini belirtmişlerdir. Ayrıca beton döşeme kalınlığının yanı sıra Hong vd. [10] tarafindan yapılan çalışmada kolon boyutu ve donatı lokasyonu IE ile tahmin edilebilmiştir. Ne yazık ki tüm bu tahminleri yapabilmek spektrumda birçok pik gözlenmesi sebebiyle çoğu zaman çok kolay olmamaktadır [11]. Bu sebeple IE için bir görüntüleme tekniği olan SIBIE (Darbe-Eko'da Spektral Genliklerin Toplanarak Görsellenmesi) tekniği Ohtsu ve Watanabe [12] tarafından geliştirilmiştir. SIBIE prosedüründe incelenecek eleman yüzeyindeki çeşitli noktaların yansıma yoğunlukları belirlenir ve tüm eleman için bütün bir resim oluşturulur. Ata (Alver) vd. [13] tarafından iki tayin noktası kullanılarak geliştirilmiş SIBIE prosedürü ile ard-germe kanalı görüntülenmiş, ardından Ohtsu ve Alver [14] tarafından boşluklu ard germe kanalının görüntülenmesi için lazer vibrometre ile temassız olarak SIBIE geliştirilmiştir. Tokai vd. [15] tarafından kıvrımlı ve zikzaklı yüzeysel çatlakların SIBIE ile görüntülenmesinin üzerine çalışılmışsa da, tek noktadan ölçüm alınması ve görüntünün simetrik oluşması sebebiyle iki çatlak türü arasında beklenen ayrımın gerçekleştirilemeyeceği ortaya konulmuştur. Daha sonra Matsuyama vd. [16] çalışmalarında bir karayoluna ait beton kolonların delaminasyon bölgesindeki boşlukları ve yüzeysel çatlak derinliği ölçümünü yerinde alınan IE ölçümleri ile mevcut yapılardaki hasarların SIBIE sayesinde görüntülenebildiğini ortaya koymuşlardır. UE yönteminde piezoelektrik ultrasonik sensör tarafından salınan elastik dalgalar malzeme içerisinde yayılır ve bir kısım enerji taban veya hasar yüzeylerinden yansır. Bu sayede biri dalga kaynağı diğeri alıcı olan iki sensör yardımıyla uçuş zamanı hesaplanarak hasarın konumu belirlenir. $\mathrm{Bu}$ esasa dayanan ultrasonik muayene hasar tespitleri, boyutsal ölçümler, malzeme karakterizasyonları vb. için kullanılmaktadır. Yöntem beton atık su borularındaki ve ard-germe kanallarındaki hasarların incelenmesinde başarılı sonuçlar doğuran çalışmalara da konu olmuştur [17, 18]. Ayrıca Parthasarathy vd. [19] tarafindan beton döşemelerdeki hasarların tespiti için radar ve ultrasonik puls eko yöntemlerinden alınan sonuçlar değerlendirilmiş ve yöntemin etkinliği belirlenmiştir. Demcenko vd. [20] bozuk bir beton yapıda hasar görmemiş tabaka kalınlığını tahmin etmek üzere katılık matris yöntemine dayalı nümerik ve ultrasonik pulsa dayalı deneysel bir çalışma yapıp, başarılı bir doğrulama gerçekleştirilmiştir. Xiongbing vd. [21] çalışmalarında ultrasonik $C$ taraması görüntüsünün hasarın büyüklüğü ile ilişkili olduğunu ve eşik değeri tarafından etkilendiğini ortaya koymuşlardır. Bunun için her hasar için ayrı eşik değeri seçerek elde ettikleri $\mathrm{C}$ taraması görüntüsünde ortalama rölatif hatayı \%33,2 oranında azaltmayı başarmışlardır. Yöntemde malzemenin heterojen yapısından kaynaklanan sinyalin sönümlenmesi ve dağılması sebebiyle 
her zaman A, B ve C taramalarını değerlendirme mümkün olmamaktadır. Ancak SAFT (Yapay Açıklıklı Odaklanma Tekniği) bu problemlerin ortadan kaldırılmasını ve betondaki hasarların gerçek bir şekilde görüntülenmesini mümkün kılmaktadır. Hoegh vd. [22] çalışmalarında betondaki çatlak ve konsolide edilmemiş bölge simülasyonlarının lokasyonlarının ve donatı ebatlarının, Ganguli vd. [23] betonarmedeki hava boşluklarının SAFT tekniği ile belirlenmesine katkı sağlamışlardır. Antonio vd. [24] tarafindan çelik donatıya sahip beton numuneler için SAFT oluşturulmasında veriler Hilbert-Huang Transformu ile işlenmiştir. İki tekniğin birlikte kullanımı ile yalnız SAFT'ın kullanımına göre daha etkin sonuçlar elde edildiği gözlenmiştir. Çelik donatı veya hava boşluğu gibi betonda yer alan farklı malzeme türlerinin belirlenmesi de önemli bir konudur. $\mathrm{Bu}$ ayrımı tanımlayabilmek için yansıyan ultrasonik sinyalin faz açısının da ayrıca göz önünde bulundurulması gerekmektedir. Faz açısının $180^{\circ}$ ye yükselmesinin kalınlığın arttığına işaret ettiği bilgisinden faydalanarak tabakalar arası sınıflandırma yapmak mümkün olmaktadır. Mayer vd. [25] tarafindan UE'den elde edilen ölçümlerden faz bilgisi elde edilerek SAFT görüntüleri yenilenmiştir. Schulze vd. [26] tarafından beton duvar numunelerde enjekte hasarları içeren germe kanalları ve ön germe sistemleri faz hassasiyetli UE ölçümleriyle incelenmiştir. Bu çalışmada metal kalınlıkları farklı olan ve bir tarafı grout ile doldurulmuş diğer tarafi ise tamamen boş bırakılmış birer ard germe kanalına sahip iki beton blok numune IE ve UE ile test edilmiştir. Böylelikle kanalların konumları ile içerilerindeki boşluğu temsil eden enjeksiyon yapılmamış bölgeler incelenmiştir. Ayrıca ard germe kılıfı metal kalınlığının ultrasonik sinyale etkisi ultrasonik faz analizi yapılarak incelenmiş ve sinyaldeki değişim belirlenmiştir. Faz analizi yardımı ile beton içerisinde gömülü farklı malzemeler ayırt edilebilmiştir.

\section{ELASTİK DALGA YÖNTEMLERİ (ELASTIC WAVE METHODS)}

\subsection{Darbe-Eko Yöntemi (Impact-Echo Method)}

1997'de Carino, Sansalone ve arkadaşları tarafindan geliştirilen Darbe-eko yöntemi malzeme içerisinde yayılan geçici gerilme pulsunun kullanılması esasına dayanmaktadır [27]. Yöntem; darbenin uygulanması, yayılan elastik dalgaların algılanması ve FFT yapılarak pik frekansların incelenmesi olmak üzere üç ana aşamadan oluşmaktadır [28]. İlk olarak küçük çelik bir bilyenin malzeme yüzeyine düşürülmesiyle oluşturulan mekanik darbe sayesinde gerilme pulsu oluşturulur ve bu gerilmeler malzeme içerisinde $\mathrm{P}, \mathrm{S}$ ve $\mathrm{R}$ dalgaları olarak yayılır ( $\mathrm{P}$ dalgası diğer dalga türlerinden daha hızlı hareket ettiği için başlıca öneme sahiptir). Bu dalgalar malzeme içindeki kusurlar ve sınır yüzeyler tarafindan yansıtılır. Yansıyan dalgalar ise darbenin oluşturulduğu yüzeye geri dönerek burada yer değiştirmeler (titreşimler) meydana getirir ve bu yer değiştirmeler yüzeydeki alıcılar tarafindan ölçülür [27]. Böylece beton içerisindeki hasarların varlığı, konumları ve tabaka kalınlığı IE yöntemi ile belirlenir.

İşlem süresince darbenin oluşturulduğu noktanın yakınına yerleştirilen bir alıcı sayesinde yansıyan dalgaların yüzeyde oluşturduğu yer değiştirmeler izlenmektedir. Fakat kaydedilen zaman-tanım aralığındaki dalga formlarında çok sayıda pik ile karşılaşılması sebebiyle, Hızlı Fourier Dönüşümü kullanarak sinyal frekans-tanım aralığında frekans spektrumu olarak incelenir (Şekil 1). Bu dönüşüm sayesinde dalga formu sinüs fonksiyonları serisine indirgenmekte ve yüksek genlik piklerini temsil eden " $f$ " frekansları ile dalga formundaki baskın frekanslar belirlenebilmektedir. $\mathrm{P}$ dalgasının malzeme içerisindeki yayılım hızı olan " $C_{p}$ " ve elde edilen " $f$ " frekans değerlerine bağlı olarak dalganın yansıdığı derinlik “ $D$ ” Eş. 1 yardımıyla hesaplanmaktadır.

$\mathrm{D}=\frac{\mathrm{C}_{\mathrm{p}}}{2 \mathrm{f}}$

\subsection{SIBIE Görüntüleme Algoritması (SIBIE Imaging Algorithm)}

Çoklu yansımalar sonucu IE sinyalinde meydana gelen çok sayıdaki pik ve bünye dalgalarının kırılmaları sebebiyle spektrumu yorumlamak karmaşık bir işlemdir [13]. Bu sebeple IE'yi geliştirmek ve verileri daha doğru yorumlamak için SIBIE görüntüleme tekniği geliştirilmiştir. SIBIE ile betondaki çatlak, boşluk, farklı malzeme vb. görüntülemesi gerçekleştirilmektedir [29]. Prosedürde öncelikle Şekil 2'de görüldüğü üzere beton en kesiti kare elemanlara (" $\Delta \mathrm{t}$ " kaydedilen dalganın örnekleme zamanı olmak üzere, boyutları en az $\mathrm{C}_{\mathrm{p}} \Delta \mathrm{t} / 2$ değerine eşit olmalıdır.) bölünür. Ardından her kare için Eş. 2 kullanılarak her elemandaki yansımadan kaynaklanan frekans değerleri elde edilir. Giriş ve çıkış arasındaki toplam uçuş mesafesi Eş. 3 ile hesaplanır.

$f_{2},=\frac{C_{p}}{r_{2}}$ ve $f_{R}=\frac{C_{p}}{R}$

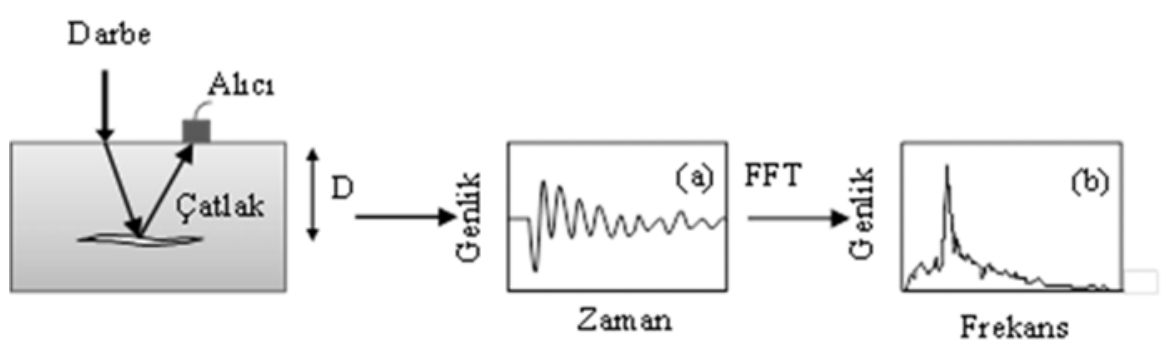

Şekil 1. IE metodolojisi a) Dalga formu b) Spektrum (IE methodology: a) Waveform b) Spectrum) 


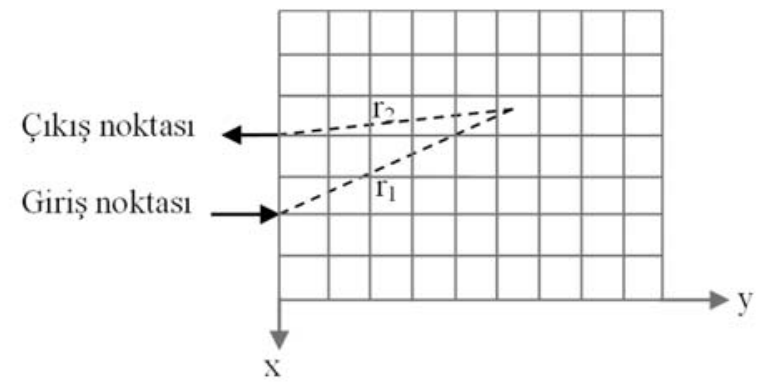

Şekil 2. Spektral görüntüleme modeli (Spectral imaging model)

$\mathrm{R}=\mathrm{r}_{1}+\mathrm{r}_{2}$

Her kare eleman için spektral genliklere tekabül eden bu iki frekans toplanır. Böylece her elemandaki yansıma yoğunlukları elde edilerek, en kesitin görüntüsü oluşturulur [14].

\subsection{Ultrasonik-Eko Yöntemi (Ultrasonic-Echo Method)}

Ultrasonik-eko (UE) yöntemi de betonun yapısını tahribatsız olarak muayene etmekte kullanılan yöntemlerden biridir. Yöntem IE'ye benzer olarak elastik dalga yayılımı esasına dayanmaktadır. Malzemede yayılan dalgalar çatlak, sınır yüzeyleri veya farklı malzeme gibi süreksizlikler tarafından yansitılır [29]. Yansitılan dalgalar kaynak görevi gören ultrasonik sensörlerin benzeri olan alıcı ultrasonik sensörler tarafından algılanıp kaydedilir ve elektrik sinyaline dönüştürülür. Ancak IE'nin aksine UE'de yayılan elastik dalgalar piezoelektrik ultrasonik sensör ile oluşturulmaktadır ve FFT dönüşümü yaparak frekans-tanım aralığında çalışmaya ihtiyaç duyulmamaktadır. Dalgaların malzeme içerisindeki yayılım hızının ve uçuş süresinin bilinmesiyle sinyalin kat ettiği mesafe, diğer bir değişle süreksizliğin yüzeyden derinliği kolaylıkla hesaplanabilirken, malzemenin nasıl bir dayanım sergileyeceği hususunda genel bir fikre sahip olunabilir [30]. Ayrica sinyale ait faz açısı bilgilerinden yola çıkarak yansıtıcı süreksizliğin özellikleri hakkında bilgi sahibi olunur. Böylece UE, hasar tespiti ve boyutsal ölçümün yanı sıra malzeme karakterizasyonuna da olanak sağlamaktadır. Tipik bir UE sistemi Şekil 3 'te gösterilmektedir.

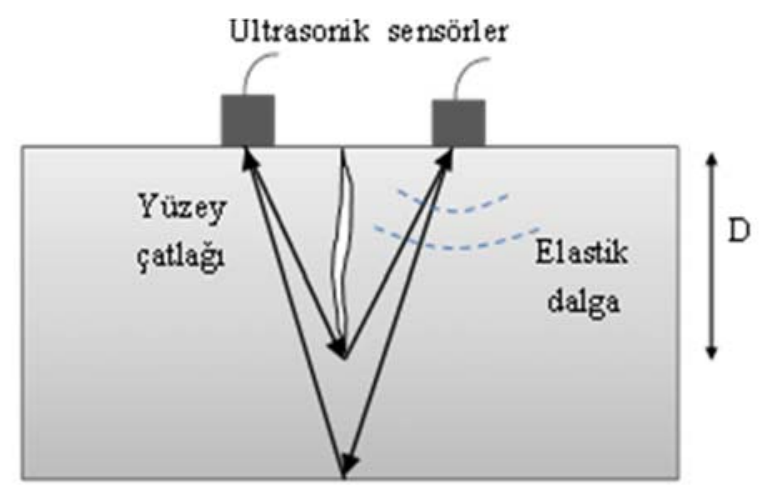

Şekil 3. Geleneksel UE çalışma prensibi (Conventional UE working principle)

\subsection{SAFT Görüntüleme Algoritması (SAFT Imaging Algorithm)}

UE prosedüründe hacimsel bir görüntülemede derinlik, yükseklik ve genişlik boyunca gerçekleştirilen taramalar ile beton hasar değerlendirmesi yapılabilmektedir [30]. Bu taramalar Şekil 4'te gösterildiği üzere A, B ve C taramaları olarak adlandırılmaktadır [31]. Ancak kesit analizinde malzemelerin heterojen yapısı sebebiyle baz1 problemler meydana gelebilmekte ve bu durum ultrasonik görüntüyü gerçeklikten saptırabilmektedir. Sinyalin sönümlenmesi ve dağılması gibi problemler incelenen nokta ile ultrasonik sensör arasındaki mesafe farkından kaynaklanmaktadır. Ultrasonik sensör ile incelenen nokta arasındaki mesafe arttıkça, sinyal varış zamanı daha yüksek değerlerde olmaktadır. Elde edilen bu zaman gecikmeleri de taranan bölgenin geometrisinde hiperbolik ve odaklanılamamıș görüntüler oluşmasına sebep olmaktadır. Bu yanılsamaları engellemek için geliştirilen SAFT tekniği ile zaman gecikmeleri düzeltilmekte ve gerçekçi bir hasar ve içyap1 görüntülenmesi sağlanmaktadır [31].

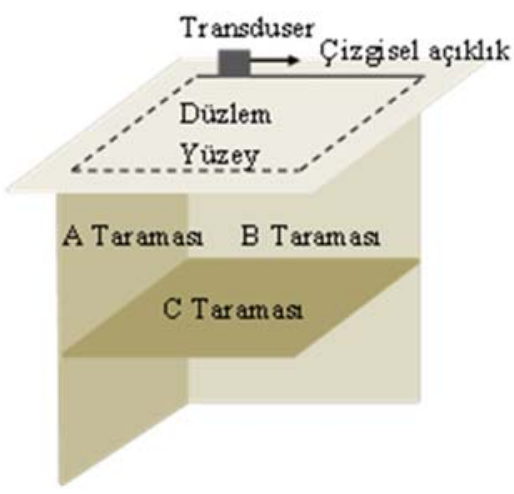

Şekil 4. Kesit görüntülemeleri [31]

(Cross-section visualisation [31])

Şekil 5a'da gösterildiği üzere malzeme yüzeyinde ultrasonik sensör "d" aralıklarla ilerlemekte iken incelenen nokta ve sensörün koordinatları sirasıyla $\left(\mathrm{x}_{\mathrm{i}}, \mathrm{y}_{\mathrm{i}}\right)$ ve $\left(\mathrm{x}_{\mathrm{n}}, \mathrm{y}_{\mathrm{n}}\right)$ olsun. Yansıma mesafesi " $\mathrm{z}_{\mathrm{i}}$ ", zaman " $\mathrm{t}_{\mathrm{i}}$ " ve zaman gecikmeleri " $\Delta \mathrm{t}_{\mathrm{i}}$ " Eş. 4, 5 ve 6 ile belirlenebilmektedir:

$\mathrm{z}_{\mathrm{i}}=\sqrt{\left(\mathrm{x}_{\mathrm{n}}-\mathrm{x}_{\mathrm{i}}\right)^{2}+\left(\mathrm{y}_{\mathrm{n}}-\mathrm{y}_{\mathrm{i}}\right)^{2}}$

$\mathrm{t}_{\mathrm{i}}=\frac{2 \mathrm{z}_{\mathrm{i}}}{\mathrm{C}_{\mathrm{p}}}$

$\Delta \mathrm{t}_{\mathrm{i}}=\frac{2}{\mathrm{C}_{\mathrm{p}}}\left[\mathrm{z}_{\mathrm{i}}-\sqrt{\mathrm{d}^{2}+\mathrm{z}_{\mathrm{i}}^{2}}\right]$

Sonuç olarak ötelenen zaman gecikmeleri yardımıyla yeni genlik değerleri Şekil 5c'deki gibi elde edilmektedir.

\section{DENEYSEL ÇALIŞMA (EXPERIMENTAL STUDY)}

\subsection{Deney Elemanlarının Tasarımı (Design of Test Specimens)}

Deneysel çalışma kapsamında $0,5 \mathrm{~m} \quad \mathrm{x} \quad 0,4 \mathrm{~m} \quad \mathrm{x} \quad 1 \mathrm{~m}$ boyutlarında, üst yüzeylerinden $20 \mathrm{~cm}$ derinlikte $5 \mathrm{~cm}$ çapında metal ard germe kanalına sahip iki adet beton blok 


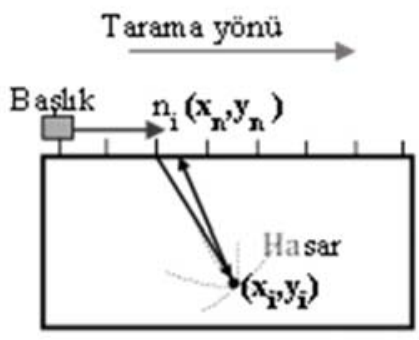

(a)

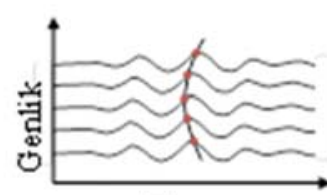

Zaman

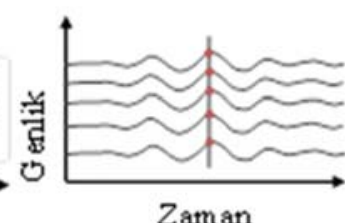

(c)

Şekil 5. a) SAFT algoritması b) Asıl yansımalar c) Düzeltilmiş yansımalar [31]

(a) SAFT algorithm b) Original echoes c) Shifted echoes [31])

Tablo 1. Deney elemanlarının özellikleri (Properties of the test specimens)

\begin{tabular}{lllll}
\hline \multirow{2}{*}{ Deney Eleman1 } & \multirow{2}{*}{$\begin{array}{l}\text { Beton } \\
\text { Sinıfi }\end{array}$} & Blok Boyutları $(\mathrm{mm})$ & \multicolumn{2}{l}{ Ard Germe Kanalı Metal Kılıf Kalınlığ1 } \\
\cline { 5 - 5 } & C30 & $500 \times 1000 \times 400$ & 50 & $\mathrm{D}(\mathrm{mm})$ \\
\hline$\# 1$ & C30 & $500 \times 1000 \times 400$ & 50 & 0.2 \\
\hline 2 & &
\end{tabular}

D: çap, t: metal kılıf kalınlığ

numune üretilmiştir (Şekil 6). Beton mikserinde hazırlanan beton kalıplara döküldükten sonra boşluk kalmaması için vibratör yardımıyla sıkıştırılarak kalıplara yerleştirilmiştir. Daha sonra numuneler 28 günlük standart küre tabi tutulmuşlardır. Beton test numunelerine ait boyutsal özellikler Tablo 1'de, üretimde kullanılan betonun türü ve karışım tasarımı ise Tablo 2'de verilmiştir. Beton bloklardan birinin ard germe kanalı $0,2 \mathrm{~mm}$, diğeri ise $2 \mathrm{~mm}$ kalınlığa sahip metal malzemeden imal edilmiştir. Numunelerin ard germe kanalları numunenin bir yarısında tamamen grout ile doldurulmuş diğer yarısında ise boşluğu temsil edecek şekilde boş bırakı1mıştır.

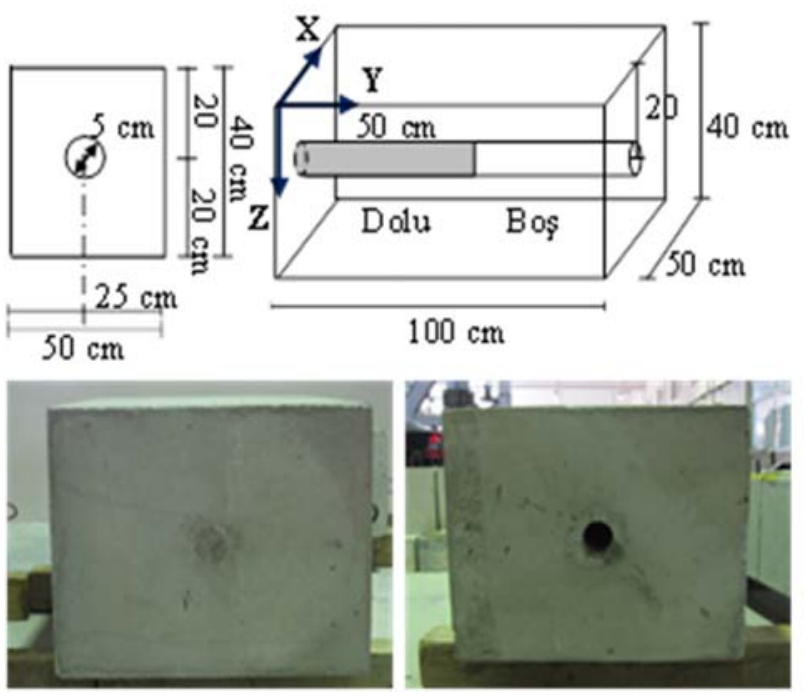

Şekil 6. Deney elemanları (Test specimens)
Tablo 2. Beton karışım tasarımı (Mix design of concrete)

\begin{tabular}{ll}
\hline İçerik & Miktar $\left(\mathrm{kg} / \mathrm{m}^{3}\right)$ \\
\hline Çimento & 330 \\
Su & 174 \\
Süper akışkanlaştırıcı & 2,8 \\
Kaba agrega No1 & 280 \\
Kaba agrega No2 & 670 \\
İnce agrega (kırma kum) & 577 \\
İnce agrega (kırma kum) & 377 \\
\hline
\end{tabular}

\subsection{IE ve UE Deneyleri (IE and UE Tests)}

IE deneylerinde elastik dalgalar $4 \mathrm{~mm}$ çapındaki çelik bilyenin beton blok numunelerin üst yüzeylerine tek noktadan $20 \mathrm{~cm}$ yükseklikten serbest düşürülmesiyle oluşturulmuştur. Elastik dalgaların yansıması sonucu yüzeyde oluşan yer değiştirmelerin algılanması için ise frekans aralığ $50 \mathrm{kHz}$ olan bir adet minyatür tip ivmeölçer kullanılmıştır. Deneyde veri toplama ünitesi olarak Tektronix TDS2014 tipi osiloskop kullanılmıştır ve örnekleme zamanı $4 \mu$ s ve her bir dalga formu için veri sayısı 2048 olarak seçilmiştir. Deneyde kullanılan test sistemi Şekil 7'de gösterilmiştir. Elde edilen dalga formları FFT ile analiz edilerek Fourier spektrumları elde edilmiştir. P-dalgasının beton blok içerisindeki yayılma hızı ultrasonik geçiş hızı deneyi ile $4200 \mathrm{~m} / \mathrm{sn}$ olarak belirlenmiştir. IE ölçümleri numunelerin her yarısında da hem dolu hem de boş ard germe kanalı üzerinde tek noktadan alınmıştır. Elde edilen veriler SIBIE tekniği ile analiz edilmiştir ve ölçümün alındığ1 noktadaki enkesitin görüntü resimleri elde edilmiştir. 

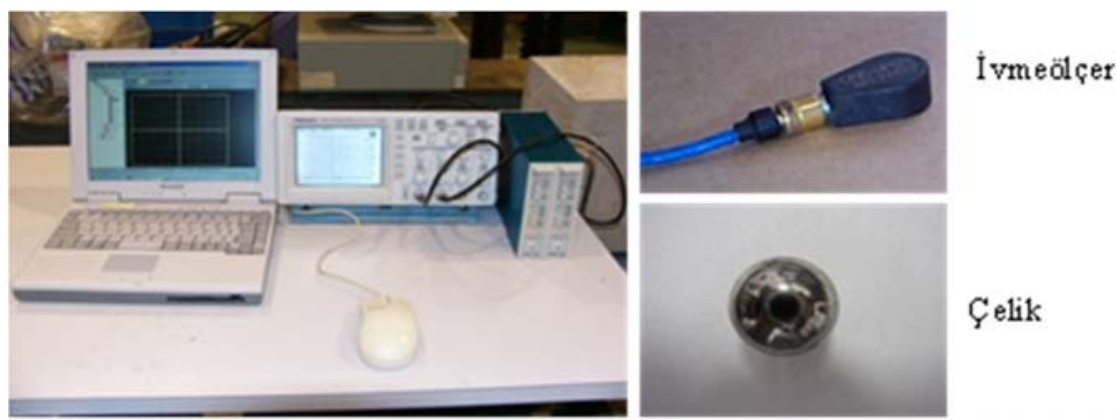

Şekil 7. Darbe-eko test sistemi; veri toplama, sensör ve darbe kaynağ1 (Impact-echo test system; data acquisition, sensor and impactor)

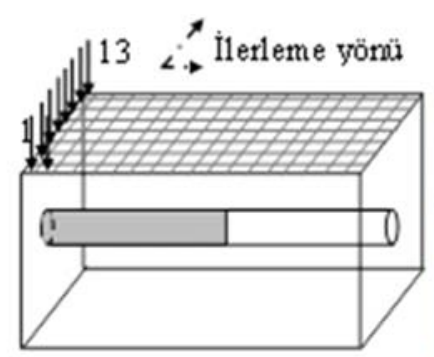

(a)

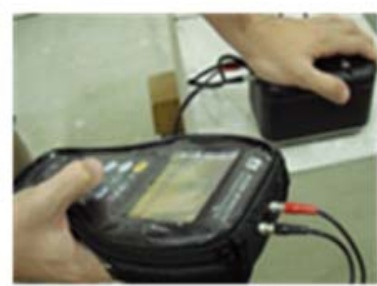

(b)
Şekil 8. a) Deney elemanlarının ultrasonik ölçüm şeması b) 24 sensörlü ultrasonik cihaz ile UE ölçümü

(a) Testing scheme b) UE testing with ultrasonic device having 24 sensors)

UE ölçümleri blokların kare elemanlara bölünen yüzeyleri üzerinde 24 sensörlü ACSYS A1220 Monolith cihazı ile cihaz başlığının orta noktası her bir kare elemana denk gelecek şekilde tutularak ilerletilmesiyle her bir kare elemandan ölçüm alarak $50 \mathrm{kHz}$ frekans aralığında yapılmıştır. (Şekil 8b) Ultrasonik ölçümlerde bütün numunenin üst yüzeyinde bir tarama ölçümü yapılmıştır. Her bir nokta için dört sinyalin ortalaması alınmış olup ölçme hataları minimize edilmiştir. Elde edilen veriler zaman-tanım aralığında SAFT prosedürü ile analiz edilmiştir. Yukarıda bahsedilen SAFT algoritması her iki numune için tekrarlanmış ve yoğunluklar içeren bölgeler ard germe kanalının lokasyonu hakkında bilgi vermiştir. Ard germe kanalındaki boşluğu temsil eden boş kısmın belirlenmesi için ise sinyallerin faz bilgilerinden faydalanılmıştır. Yansıyan dalganın fazına bağlı olarak hangi malzeme tarafından yansıtıldığı değerlendirilmiş̧tir.

\section{SONUÇLAR VE TARTIŞMALAR (RESULTS AND DISCUSSIONS)}

\subsection{SIBIE Bulguları (SIBIE Results)}

IE ölçümleri sonucunda elde edilen verilere SIBIE analizi uygulanmış ve Şekil 9a ve Şekil 9b'de gösterilen $2 \mathrm{~mm}$ kalınlıktaki ard germe kanalına sahip numunenin ard germe kanalının boş ve dolu kısımlarını belirten görüntüler elde edilmiştir. Şekil 9'da numunenin IE ölçümü yapıldığı nokta altında 50x40 $\mathrm{cm}^{2}$ 'lik alanda $\mathrm{x}-\mathrm{Z}$ enkesitine ait görüntüler verilmektedir. Ard germe kanalı beyaz çember ile temsil edilmiştir. Ayrıca verilen genlik değerleri normalize edilmiştir. Şekilde kanalın boş kısmı görüntülenmiş olup, yüksek genlik değerleri koyu renkle belirtilmiştir. Her iki görüntü kıyaslandığında SIBIE tekniği ile ard germe kanalındaki boş ve dolu kısımların başarıyla görüntülenebildiği ve genlik değerleri ile de bu kısımların ayrımlarının yapılabildiği görülmektedir. Darbe-eko yönteminde faz analizi yapmak mümkün olmadığından metal ve hava ayırımını yapmak olanaksızdır. Bu sebeple yalnızca $2 \mathrm{~mm}$ kalınlığındaki deney elemanına IE testleri uygulanmış ve burada boş ve dolu kısmın IE yöntemi ile ayırt edilmesi amaçlanmıştır.

\subsection{SAFT Bulguları (SAFT Results)}

SAFT tekniği ile de beton blokların kesitlerinin resimleri oluşturulmuş olup, yoğunluğu fazla olan bölgeler belirlenebilmiştir. Şekil 10'da 0,2 mm kalınlığında ard germe kanalına sahip beton bloğun $\mathrm{x}=0,25$ m'de $\mathrm{y}-\mathrm{z}$ kesitindeki D taraması ile elde edilen SAFT ve faz analizi sonuçları gösterilmektedir. Kanalın dolu ve boş kısımları görüntülenmiş ve dolu kısımda düşük, boş kısımda ise yüksek genlik değerleri elde edilmiştir. Benzer şekilde dalgaların beton bloğun tabanından yansımaları da görülmektedir. Dolu kısımda görülen bir kısım yansımaların grout enjeksiyonunun tam yapılamaması sonucu oluşan boşluklardan veya ard germe kanalı üzerindeki betonun iyice sıkıştırılmamasından kaynaklandığ 1 düşünülmektedir. Şekil 11 ve 12 'de beton blokların $0,198 \mathrm{~m}$ derinlikte C taramalarından (x-y kesiti) elde edilen SAFT ve faz analizi sonuçları sunulmuştur. Bu derinlik yaklaşık olarak ard germe kanalının lokasyonuna denk gelmektedir. Bu resimlerden de genlik ve faz farkları yardımıyla her iki numunenin dolu ve boş kısımlarının başarılı bir şekilde ayırt edilebildiği görülmektedir. Her iki blokta da dolu kısımda görülen yansımaların ve dolayısıyla bir miktar yüksek genlik değerlerinin grout enjeksiyonunun tam yapilamamas1 sonucu oluşan boşluklardan veya ard germe kanalı üzerindeki betonun iyice sıkıştırılmamasından kaynaklandığı düşünülmektedir. Şekil 10 ve 11 aynı numunenin farklı düzlemlerdeki enkesit görüntüleridir ve Şekil 11'de yani bloğun üstten görünüş enkesitinde dolu kısımlardaki anomaliler daha fazla belli olmakla birlikte Şekil 10'daki yan görünüş enkesitinde bu anomaliler daha az görünmektedir. 
(a)

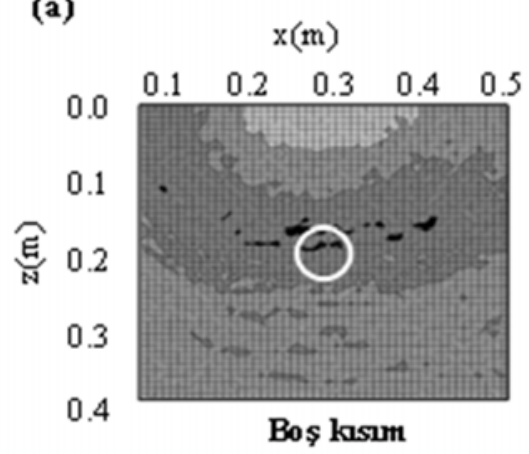

(b)

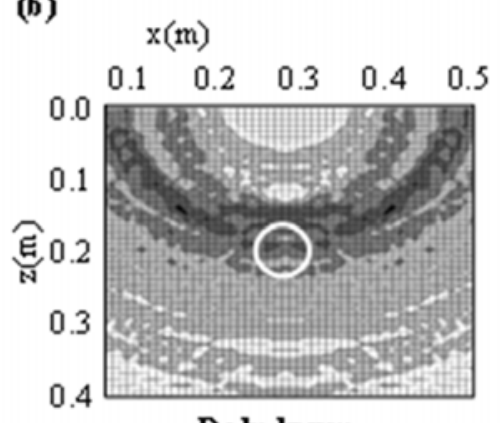

Dolu kssum

Şekil 9. 2 mm kalınlığındaki ard germe kanalına sahip deney elemanının SIBIE analizi sonuçları

a) Kanalın boş olduğu enkesit b) Kanalın dolu olduğu enkesit

(Results of SIBIE analysisof the test specimen having 2 mm-thick tendon duct a) Empty part b) Grouted part)
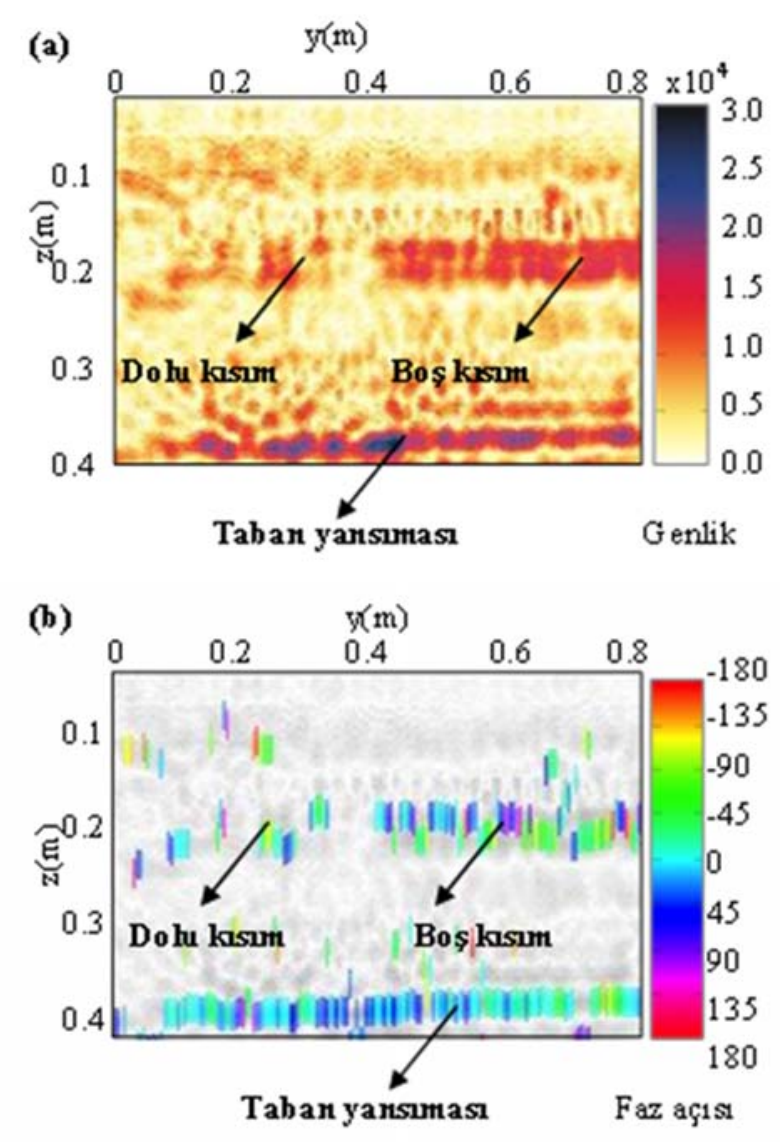

Şekil 10. $\mathrm{t}=0,2 \mathrm{~mm}$ kalınlıkta ard germe kanalına sahip beton blokta $\mathrm{x}=0,25 \mathrm{~m}$ y-z kesitinde a) SAFT analizi b) Faz analizi ( $y-z$ section image of the specimen having $t=0.2$ mm-thick tendon duct at $x=0.25 \mathrm{~m}$ a) SAFT analysis $b$ ) Phase analysis)

Şekil 11b'de verilen faz analizi sonuçlarında metal kalınlığının az olması sebebiyle ultrasonik sinyalin faz değişimine uğramadığı, o bölgede sadece hava boşluğu varmış gibi değerlendirildiği ve bu sebeple de fazda değişim gözlenmediği görülmektedir. Fakat $2 \mathrm{~mm}$ metal kalınlığındaki ard germe kanalı içeren deney elemanının faz analizi sonuçlarının verildiği Şekil 12b'de ard germe kanalı metal kalınlığının fazla olması sebebiyle ultrasonik sinyalin faz açısının 90 dereceden fazla değiştiği gözlenmiştir.

$\mathrm{Bu}$ durum tabaka kalınlığının faz değişimindeki etkisini ve sinyalin metalden mi yoksa boşluktan mı kaynaklandığının ayırt edilebildiğini kanıtlamıştır. Ayrıca ard germe kanalının kılıf kalınlığının artmasıyla faz açısında gözlenen 

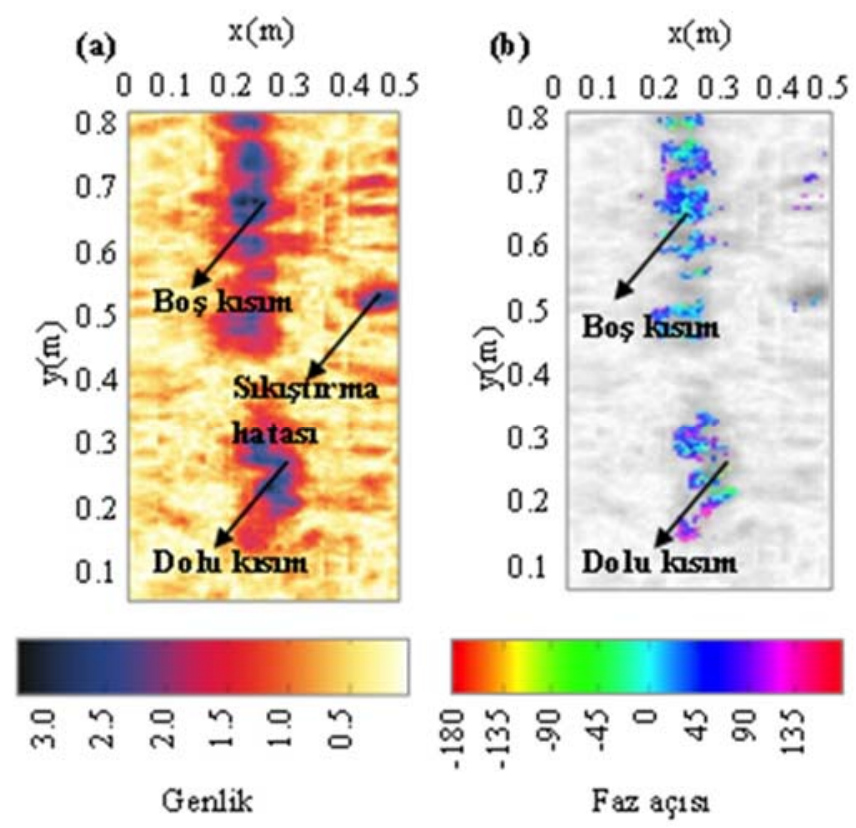

Şekil 11. $\mathrm{t}=0,2 \mathrm{~mm}$ kalınlıkta ard germe kanalına sahip beton blokta $\mathrm{z}=0,198 \mathrm{~m} \mathrm{x}-\mathrm{y}$ kesitinde a) SAFT analizi b) Faz analizi ( $\mathrm{x}-\mathrm{y}$ section image of the specimen having $\mathrm{t}=0.2 \mathrm{~mm}$-thick tendon duct at $\mathrm{z}=0.198 \mathrm{~m}$ a) SAFT analysis $\mathrm{b}$ ) Phase analysis)

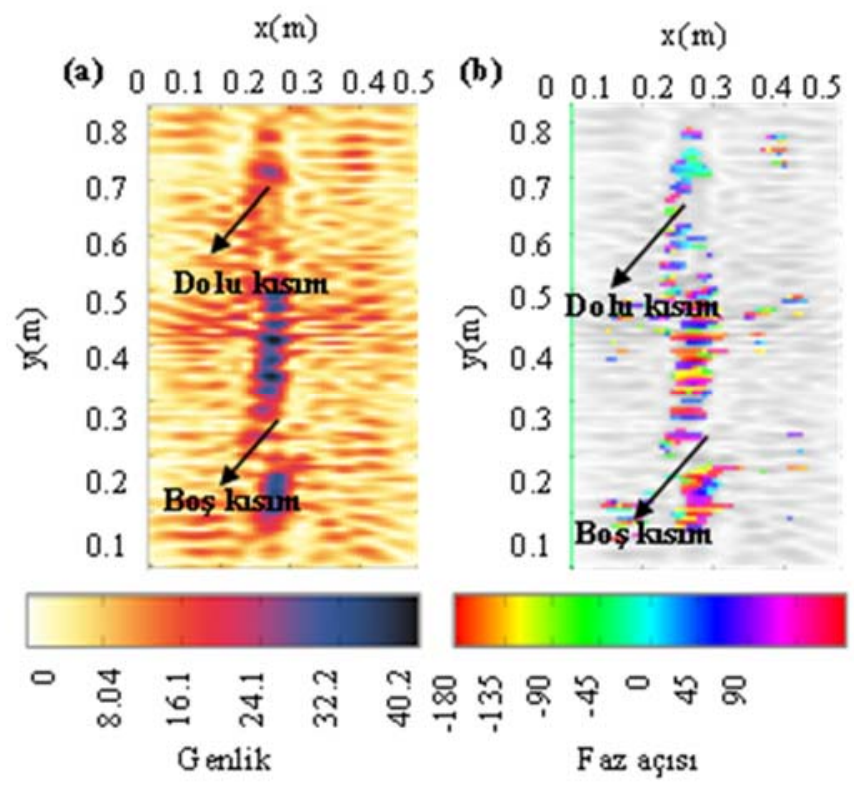

Şekil 12. $\mathrm{t}=2 \mathrm{~mm}$ kalınlıkta ard germe kanalına sahip beton blokta $\mathrm{z}=0,198 \mathrm{~m} \mathrm{x}-\mathrm{y}$ kesitinde a) SAFT analizi b) Faz analizi. ( $\mathrm{x}$-y section image of the specimen having $\mathrm{t}=2 \mathrm{~mm}$-thick tendon duct at $\mathrm{z}=0.198 \mathrm{~m}$ a) SAFT analysis $\mathrm{b}$ ) Phase analysis)

değişiklikle birlikte boşluk (hava) ve çelik arasındaki akustik empedans malzeme karakteristiği ayrımı yapılabilmiştir.

\section{SONUÇLAR (CONCLUSIONS)}

$\mathrm{Bu}$ çalışmada boşluk içeren metal ard germe kanallarına sahip beton blok numunelere IE ve UE ölçümleri yapılmış, SAFT ve SIBIE teknikleri ile numunelerin boşluk durumları görüntülenmiştir. Ayrıca faz açısı bilgisinden faydalanarak bu görüntüler doğrulanmış ve farklı malzeme kalınlıklarının sonuçlara etkisi belirlenmiştir. Çalışma sonunda şu sonuçlar elde edilmiştir: Ard germe kanallarının lokasyonları ve boş kısımları görüntülenmiştir. Elde edilen sonuçlar 1-3 mm hata ile oldukça memnuniyet vericidir. Yüksek frekansa sahip sensörlerle boşlukları belirlemenin daha kolay olabileceği düşünülmektedir.

Deney numunelerinin küçük boyutlarda olması ve tamamen sıkıştırılamamış olması sebebiyle kolay yorumlanabilir sinyaller elde edilememiştir. $\mathrm{Bu}$ sebeple resimlerde 
sıkıştırma hataları da görüntülenmiştir. Ard germe kanalı metal kalınlığının değiştirilmesi sonuçları etkilemiştir. Kalınlığın arttırılmasıyla ultrasonik sinyaldeki faz değişimi açıkça belirlenebilmiştir.

\section{SIMGELER (SYMBOLS)}

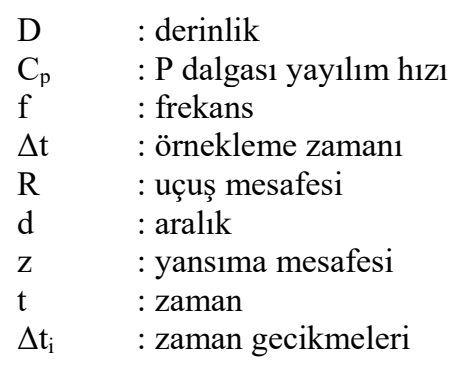

\section{TEŞEKKÜR (ACKNOWLEDGEMENT)}

Bu çalışmanın yürütülmesinde sağladığı finansal destek için Türkiye Bilimsel ve Teknolojik Araştırma Kurumu'na (TÜBİTAK, Proje No: 110M585) ve deneysel sonuç analizlerindeki destekleri için BAM-Federal Malzeme Araştırma ve Test Enstitüsü'nden Boris Milmann'a teşekkürü borç biliriz.

\section{KAYNAKLAR (REFERENCES)}

1. Jaeger B.J., Sansalone M.J. ve Postron R.W., Detecting Voids in Grouted Tendon Ducts of Post-Tensioned Concrete Structures Using the Impact-Echo Method, ACI Structural Journal (ACI Struct. J.), 93, 462-473, 1996.

2. La H.M., Gucunski N., Dana K. ve Kee S.H., Development of an Autonomous Bridge Desk Inspection Robotic System, Journal of Field Robotics, 34, 1489-1504, 2017.

3. Zhu J. and Popovics J., Imaging Concrete Structures Using Air-Coupled Impact-Echo, Journal of Engineering Mechanics (J. Eng. Mech.), 133, 628-640, 2007.

4. Epasto G., Proverbio E. ve Venturi V., Evaluation of Fire-Damaged Concrete Using Impact-Echo Method, Materials and Structures (Mater. Struct.), 43, 235-245, 2010.

5. Bhaskar S., Srinivasan P., Murthy S.G.N., Ravisankar, K. ve Iyer, N.R., Thickness Measurement and Detection of Tendon Ducts in Concrete Slab Specimen Using Impact-Echo Technique, National Seminar\&Exhibition on Non-Destructive Evaluation, NDE-2011, 286-290, 810 Aralik, 2012.

6. Olson L.D., Tinkey Y. ve Miller P., Concrete Bridge Condition Assessment with Impact Echo Scanning, Emerging Technologies for Material, Design, Rehabilitation, and Inspection of Roadway Pavements, 59-66, 2011.

7. Chaudhary M.T.A., Effectiveness of Impact Echo Testing in Detecting Flaws in Prestressed Concrete Slabs, Construction and Building Materials (Constr. Build. Mater.), 47, 753-759, 2013.
8. Azari H. ve Nazarian S., Sensitivity of Two Stress Wave-Based Methods for Nondestructive Evaluation of Concrete Slabs, Journal of Infrastructure Systems (J. Infrastruct. Syst.), 23 (4), 04017011/1-9, 2017.

9. Gomez P., Fernando-Alvarez J.P., Ares A. ve Fernandez E., Guided-Wave Approach for Spectral Peaks Characterization of Impact-Echo Tests in Layered Systems, Journal of infrastructure Systems, (J. Infrastruct. Syst.), 23 (4), 04017009/1-10, 2017.

10. Hong S.U., Na J.H., Kim S.H. ve Lee Y.T., Estimation of Slab Depth, Column Size and Rebar Location of Concrete Specimen Using Impact Echo Method, Materials Research Innovations (Mater. Res. Innovations), 19, 1167-1171, 2015.

11. Alver N. ve Wiggenhauser H., Modified SIBIE Procedure for Ungrouted Tendon Ducts Apllied to Scanning Impact-Echo, Construction and Building Materials (Constr. Build. Mater.), 24 (12), 2388-2392, 2010.

12. Ohtsu M. ve Watanabe T., Stack Imaging of Spectral Amplitudes based on Impact-Echo for Flaw Detection, NDT\&E International, 35 (3) 189-196, 2002.

13. Ata Alver N., Mihara S. ve Ohtsu N., Imaging of Ungrouted Tendon Ducts in Prestressed Concrete by Improved SIBIE, NDT\&E International, 40 (3), 258264, 2007.

14. Ohtsu M. ve Alver N., Development of Non-Contact SIBIE Procedure for Identifying Ungrouted Tendon Duct, NDT\&E International, 42 (2), 120-127, 2009.

15. Tokai M., Ohkubo T. ve Ohtsu M., Estimation of Surface-Crack Depth in Concrete by Scanning SIBIE Procedure, NDTCE'09, Non-Destructive Testing in Civil Engineering, Nantes, Fransa, 30 Haziran-3 Temmuz, 2006.

16. Matsuyama K., Yamada M. ve Ohtsu M., On-Site Measurement of Delamination and Surface Crack in Concrete Structures by Visualized NDT, Construction and Building Materials (Constr. Build. Mater.), 24, 2381-2387, 2010.

17. Iyer S., Sinha S.K., Pedrick M.K. ve Tittmann B.R., Evaluation of Ultrasonic Inspection and Imaging Systems for Concrete Pipes, Automation in Construction (Autom. Constr.), 22, 149-164, 2012.

18. Krause M., Milmann B., Schickert M. ve Mayer K., Investigation of Tendon Ducts by means of Ultrasonic Echo Methods: A Comparative Study, ECNDT 2006, Berlin, Almanya, 25-29 Eylül, 2006.

19. Parthasarathy S., Murthy S.G.N., Wiggenhauser H. ve Iyer N.R., Application of Radar and Ultrasonic Pulse Echo for Testing Concrete Structures, NDTCE'09, NonDestructive Testing in Civil Engineering, Nantes, Fransa, 30 Haziran-3 Temmuz, 2009.

20. Demcenko A., Visser H.A. ve Akkerman R., Ultrasonic Measurements of Undamaged Concrete Layer Thickness in a Deteriorated Concrete Structure, NDT\&E International, 77, 63-72, 2016.

21. Xiongbing L., Yilin W., Peijun N., Hongwei H. ve Yongfeng S., Flaw Sizing Using Ultrasonic C-Scan Imaging with Dynamic Thresholds, Insight - NonDestructive Testing and Condition Monitoring, 59 (11), 603-608, 2017. 
22. Hoegh K., Khazanovich L., Ferraro C. ve Clayton D. Ultrasonic Linear Array Validation via Concrete Test Blocks, 41th Annual Review of Progress in Quantitative Nondestructive Evaluation, Idaho, 1650, 83-93, 2015.

23. Ganguli A., Rappaport C.M., Abramo D. ve WadiaFascetti S., Synthetic Aperture Imaging for Flaw Detection in a Concrete Medium, NDT\&E International, 45, 79-90, 2012.

24. Antonio O.V.M. ve Hirose S., Ultrasonic Imaging of Concrete by Synthetic Aperture Focusing Technique Based on Hilbert-Huang Transform of Time Domain Data, Materials Transactions, 53, 621-626, 2012.

25. Mayer K., Langenberg K.J., Krause M., Milmann B. ve Mielentz F., Characterization of Reflector Types by Phase-Sensitive Ultrasonic Data Processing and Imaging, Journal of Nondestructive Evaluation, 27, 3545, 2008.

26. Schulze S., Krause M., Mayer K., Redmer B. ve Wiggenhauser $H$. Grouting Defects Localized by Ultrasonic Testing Including Phase Evaluation, NDE/NDT for Structural Materials Technology for Highways \& Bridges, 25 Ağustos, 2014.
27. Sansalone M.J. ve Streett W.B., Impact-Echo: Nondestructive Evaluation of Concrete and Masonry, Bullbrier Press, Ithaca, NY, 1997.

28. Ohtsu M., Ohno K. ve Tokai M., Visualized NDT for Concrete Cracking by SiGMA-AE and SIBIE, NDT for Safety, Prag, Çek Cumhuriyeti, 189-196, 7-9 Kasım, 2007.

29. Schickert M., Three-Dimensional Ultrasonic Imaging of Concrete Elements Using Different SAFT Data Acquisition and Processing Schemes, 41st Annual, Review of Progress in Quantitative Nondestructive Evaluation, AIP Conference Proceedings, 1650, 104113, 2015.

30. Yazıcıoğlu S. ve Bozkurt N., The investigation of the mechanical properties of structural lightweight concrete produced with pumice and mineral admixtures, Journal of the Faculty of Engineering and Architecture of Gazi University, 21 (4), 675-680, 2006.

31. Schickert M., Krause M. ve Müller W., Ultrasonic Imaging of Concrete Elements Using Reconstruction by Synthetic Aperture Focusing Technique, Journals of Materials in Civil Engineering (J. Mater. Civ. Eng.), 235-246, 2003. 